\title{
Cerebrospinal Fluid Leak in Transnasal Transsphenoidal Surgery for Pituitary Adenoma and its Management
}

\author{
https://doi.org/10.47210/bjohns.2021.v29i1.409
}

Sanajeet Singh, ${ }^{1}$ Ravi Roy, ${ }^{1}$ Vaibhav A Chandankhede, ${ }^{1}$ Sunil Goyal, ${ }^{1}$ M S Sridhar, ${ }^{2}$ Devendra Kumar Gupta ${ }^{1}$

\section{Introduction}

\section{ABSTRACT}

Over the past few decades endoscopic transnasal transsphenoidal (ETNTS) approach has been practised for excision of pituitary tumours which has minimised the rate of complications and morbidity. However, cerebrospinal fluid (CSF) leak remains a frequent complication requiring efficient management. Various skull-base repair techniques have been described in the literature all along, but there is no universal protocol for the same. Our study aims to determine an ideal strategy for skull-base repair following ETNTS surgery and suggest a protocol at the tertiary centre for the same.

\section{Materials and Methods}

In this prospective study, patients with pituitary adenoma undergoing ETNTS excision from January 2017 to May 2019 were included. Data were collected based on the intraoperative findings of grade of CSF leak following excision, surgical method for skull-base repair, biomaterials used, and recurrence of CSF leak postoperatively and its management.

\section{$\underline{\text { Results }}$}

A total of 141 patients between 10 to 74 years of age (mean age 42.6) underwent ETNTS excision of pituitary adenoma. Intraoperative CSF leak was observed in $30.5 \%$ patients with $14.1 \%$ of grade I, $8.5 \%$ of grade II and $7.8 \%$ of grade III and repair was done with fat closure, multilayer closure and with naso-septal flap, respectively. Postoperative recurrence of CSF leak was found in $2.83 \%$ of total cases and $9.3 \%$ of patient with intraoperative leak, which were managed appropriately. Overall closure rate was $100 \%$ with no further recurrence of CSF leak.

\section{Conclusion}

Surgical repair of skull-base in CSF leak is challenging and requires management in careful and graded fashion for favourable outcome.

\section{$\underline{\text { Keywords }}$}

Pituitary Adenoma; Endoscopic Surgery, Transnasal Transsphenoidal; Cerebrospinal Fluid Leak, Grades; Skull Base Repair Techniques

$\mathrm{I}$ $\mathrm{n}$ the late 20th century, endoscopic transnasal transsphenoidal (ETNTS) approach was first used as a method for excision of the pituitary tumours. ${ }^{1}$ Since then it has evolved as a preferred method for excision of

1 - Department of ENT, Army Hospital (Research \& Referral), Delhi

2 - Department of Neurosurgery, Army Hospital (Research \& Referral), Delhi

\section{Corresponding author:}

Dr Ravi Roy

email: rroy76@yahoo.co.in the sellar and parasellar lesions, as well as for the repair of skull-base. The advancement in better optics and highdefinition technology has enhanced the effectiveness in outcome, hence it has become the method of choice for surgeons over transcranial approach. ${ }^{2}$ ETNTS gives safe and direct access to the site of tumour causing comparatively less morbidity. However, cerebrospinal fluid (CSF) leak is an established and grave complication associated with the procedure following excision of the tumour that warrants instantaneous management. ${ }^{3}$ There are various techniques for skull-base repair, but there is no universal protocol for repair after ETNTS excision of 
the pituitary tumours. The surgical repair of the skullbase and closure of the CSF leak requires appropriate strategy individualised depending on the eventuality in each case. We aim to determine the ideal strategy for repair of the skull-base following ETNTS excision of the pituitary tumours and suggest a protocol at tertiary care centre for the same.

\section{Materials and Methods}

A prospective study was performed jointly at Department of Otorhinolaryngology Head and Neck Surgery and Department of Neuro-surgery of a tertiary centre in North India, after the approval of the institutional ethics committee. All patients of pituitary adenoma undergoing ETNTS excision from January 2017 to May 2019 were included in the study. Patients undergoing microscopic TNTS and medical management were excluded.

Our aim was to determine the strategy for the skullbase repair following ETNTS excision of the pituitary tumor depending on the grades of CSF leak. The objectives of this study includes.

1. to grade the intraoperative CSF leak during ETNTS, and repair the skull-base following excision of the tumour;

2. to evaluate recurrence of the CSF leak postoperatively; and

3. to suggest a protocol at the tertiary centre for skull base repair based on our institutional experience.

After preoperative examination and evaluation of the patients for the symptoms, data were collected including age, gender, complaints, imaging studies, and per-operative findings. Contrast-enhanced magnetic resonance imaging of brain and computerised tomography scan of nose and paranasal sinuses of the patients undergoing ETNTS were analysed and preparedness for the anticipated CSF leak was done.

Standard operating procedure was followed under general anaesthesia for TNTS excision of pituitary tumours, with $4 \mathrm{~mm} 0^{\circ}$ rigid endoscope. After the excision of the tumour, CSF leak, if any, was assessed intraoperatively under direct vision and grading of the leak was done as mentioned in the Table I. ${ }^{4}$
Table I: Grade of CSF leak ${ }^{4}$

\begin{tabular}{|c|c|}
\hline GRADE & DESCRIPTION \\
\hline 0 & No leak \\
\hline I & $\begin{array}{c}\text { Small weeping leak on Valsalva } \\
\text { manoeuvre }\end{array}$ \\
\hline II & Moderate leak \\
\hline III & Large leak \\
\hline
\end{tabular}

Closure was done using various methods and materials depending on the grade of CSF leak encountered. The autologous graft materials included fat harvested from the thigh or abdomen; abdominal fat was used in cases requiring only fat for closure. Other autologous grafts used in our patients included tensor fascia lata (TFL), pedicled nasoseptal (Hadad's) flap and septal cartilage harvested. Biomaterials like tissue glue (Tisseel ${ }^{\circledR}$ ), surgicel and gelfoam were used. Donor sites (abdomen and thigh) for fat and TFL was closed in layers.

Grade 0 CSF leak was managed without any closure and only surgicel was placed in the sellar cavity. Grade I CSF leak was repaired using fat alone with surgicel and tissue glue as required. Multilayer closure using fat, TFL, surgicel and tissue glue was done in Grade II CSF leak. Grade III CSF leak was managed by closure with multilayer and naso-septal flap as required along with surgicel and tissue glue. After closure of the CSF leak, nasal cavity was packed with merocel nasal pack, which were removed after 72 hours.

Postoperative CSF leak was observed in few patients. Patients who had recurrence of CSF leak were managed with combined gasket closure technique using septal cartilage, naso-septal flap and augmenting it with multilayering of fat and TFL. In 4 patients lumbar drain was used, of which one had Grade II CSF leak while the other 3 had Grade III leak.

\section{Results}

A total of 141 patients who underwent ETNTS were included in our prospective study from Jan 2017 to May 2019. The patients belonged to the age ranged between 10 to 74 years with the mean of 42.6 years. Eighty- 
Table II: Types of CSF leak, its repair and outcome

\begin{tabular}{|c|c|c|c|c|c|c|c|}
\hline & & & & & & \\
\hline
\end{tabular}

seven patients were male, and there was marginal male preponderance, with male: female ratio of 1.6.

In our study, intraoperative CSF leak was observed in total of $30.5 \%$ patients $(n=43)$, with $14.1 \%(n=20)$ of grade I, 8.5\% $(\mathrm{n}=12)$ of grade II and $7.8 \%(\mathrm{n}=11)$ of grade III. (Table II)

The various closure method used for intraoperative CSF leak were fat closure in $46.5 \%(n=20)$ of patients with grade I CSF leak; patients with grade II CSF leak $27.9 \%(n=12)$ required multilayer closure using fat, TFL and other biomaterials, wherein few patients $(n=3)$ with grade III CSF leak were also repaired with the multilayer technique; Hadad flap was used in $18.6 \%$ $(n=8)$ of patients with grade III CSF leak. No patient had donor site complication such as haematoma or wound infections.

The postoperative recurrence of CSF leak was found in 4 patients $(2.84 \%$ of total and $9.3 \%$ of patient with intraoperative leak), while no leak was seen postoperatively in patients with no intraoperative CSF leak. All 4 patients with post-operative recurrence of CSF leak were initially managed conservatively, of which only one resolved, [Table II]. Remaining 3 patients were managed with either Hadad Flap or Gasket Technique [Table II]. Overall closure rate achieved after repair of recurrence of CSF leak was $100 \%$ with no re-recurrence with a follow-up of ranging from 6 to 18 months.

Lumbar drain was used in 4 patients with postoperative CSF leak during the initial period of this study. One patient recovered, while the other 3 developed meningitis. Thereafter the use of lumbar drain was discontinued at our centre.

Statistical comparison (Table III) using Fisher's exact test, in grade III CSF leak of recurrence with the type of closure was found not significant $(\mathrm{p}=0.151)$ in our study, however, studies needs to be carried out with larger sample to obtain true significance.

\section{Discussion}

In our study of 141 Indian patients who underwent ETNTS excision of pituitary adenoma, the incidence of intraoperative CSF leak was $30.5 \%$ which is comparable to the present literature (11.5\% to $37.4 \%$ ), but most of 
Table III: Statistical comparison in grade III CSF leak

\begin{tabular}{|c|c|c|c|c|c|}
\hline $\begin{array}{l}\frac{y}{4} \\
\frac{1}{3} \\
\frac{5 x}{0} \\
0 \\
\frac{51}{6} \\
\frac{\pi}{0}\end{array}$ & z & 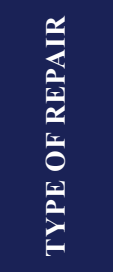 & 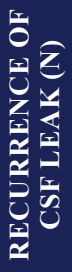 & 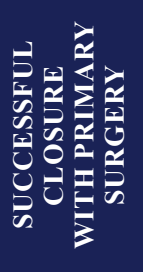 & 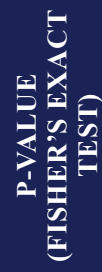 \\
\hline \multirow[b]{2}{*}{ III } & \multirow[b]{2}{*}{11} & $3 x$ & 2 & 1 & \multirow[b]{2}{*}{0.151} \\
\hline & & $\begin{array}{c}8 x \\
\text { Hadad } \\
\text { flap }\end{array}$ & 1 & 7 & \\
\hline Total & 11 & & 3 & 8 & \\
\hline
\end{tabular}

them are analysed retrospectively whereas our study was conducted prospectively. ${ }^{1,5-7}$

Postoperative recurrence of CSF leak was 2.83\% $(\mathrm{n}=4)$ in our study which is low compared to the existing published data (11.5\%). ${ }^{1,8}$ Recurrence of the high-low CSF leak such as grade II and III required a step-up closure method which includes use of Hadad flap and gasket method using septal cartilage buttress. Donor sites such as abdomen and thigh for fat and TFL did not have any complication such as hematoma or infection. ${ }^{9}$

No postoperative CSF leak was found in patients with intraoperative grade $0 \mathrm{CSF}$ leak which is significant. ${ }^{5}$ No CSF leak was seen postoperatively in patients with no intraoperative CSF leak which is contradictory with the literature. ${ }^{8,10}$

Also, in our study use of only fat for repair of grade I CSF leak was sufficient without any postoperative leak rather than an overdoing repair as described in literature such as multilayer method or dural graft repair. ${ }^{10,11}$

In grade II CSF leak, multilayer method was adequate with minimal $(n=1)$ recurrence rate. Grade III CSF leak required a robust repair with cartilage buttress in recurrence cases. ${ }^{12,13}$ Hadad flap repair was found to have more successful closure with single recurrence.

Multilayer method sufficed the repair technique for most cases of high-flow CSF leak. However, augmentation with the Hadad flap showed a fair outcome in our study and reduced the recurrence rate. It
Table IV: Proposed protocol for skull--base repair in CSF leak following ETNTS excision of pituitary tumours

\begin{tabular}{|c|c|}
\hline $\begin{array}{c}\text { GRADE OF CSF } \\
\text { LEAK }\end{array}$ & CLOSURE METHOD \\
\hline 0 & Surgicel \\
\hline I & Fat \\
\hline II & Multilayer \\
\hline III & Hadad flap \\
\hline Recurrence & $\begin{array}{c}\text { Combined Hadad's flap }+ \\
\text { Gasket technique }\end{array}$ \\
\hline
\end{tabular}

is comparable with the present literature. ${ }^{13,14}$ Moreover, Hadad flap can be used with caution and maybe preserved for situations of CSF re-leak. ${ }^{15,16}$ Its restricted use can help in reducing the morbidity as well.

Intraoperative use of lumbar drain was not necessary as mentioned in literature preoperatively or intraoperatively. Use of lumbar drain in our study showed significant rate of meningitis which is consistent with the present literature of $25 \%$ for different grades. ${ }^{17,18}$ Hence it can be discouraged as a part of management in post ETNTS CSF leak. Overall successful closure rate was comparable and significant.

In view of the above, considering a significant sample size of the study and the outcome achieved, we propose a protocol for repair of skull-base following ETNTS excision of pituitary tumour in Table IV.

\section{Conclusion}

Surgical repair of skull-base in CSF leak is challenging. It has to be managed careful and graded fashion to gain a favourable outcome, reduced hospital stay and less morbidity to the patient, eventually improving the quality of life. Endoscopic repair of the sella following excision of the pituitary tumour has been found to have the desired outcome although there is a learning curve for the surgeon. 


\section{References}

1. Endoscopic Cranial Base and Pituitary Surgery, An Issue of Otolaryngologic Clinics of North America Volume 49-1 - 1st Edition sindwani/978-0-323-41763

2. Aiyer RG, Upreti G. Endoscopic Endo-nasal Trans-Sphenoidal Approach for Pituitary Adenomas: A Prospective Study. Indian J Otolaryngol Head Neck Surg [Internet]. 2019 Aug 19 [cited 2019 Nov 27]; Available from: https://doi.org/10.1007/s12070019-01725-8

3. Watkinson JC, Clarke RW, editors. Scott-Brown's Otorhinolaryngology and Head and Neck Surgery, Eighth Edition: 3 volume set. 8 edition. Boca Raton: CRC Press; 2018. $4356 \mathrm{p}$

4. Park J-H, Choi JH, Kim Y-I, Kim SW, Hong Y-K. Modified Graded Repair of Cerebrospinal Fluid Leaks in Endoscopic Endonasal Transsphenoidal Surgery. J Korean Neurosurg Soc. $2015 \mathrm{Jul} ; 58(1): 36-42$

5. Romero ADCB, Nora JE, Topczewski TE, Aguiar PHP de, Alobid I, Rodriguéz EF. Cerebrospinal fluid fistula after endoscopic transsphenoidal surgery: experience in a spanish center. Arquivos de Neuro-Psiquiatria. 2010 Jun;68(3):414-7

6. Strickland BA, Lucas J, Harris B, Kulubya E, Bakhsheshian $\mathrm{J}$, Liu C, et al. Identification and repair of intraoperative cerebrospinal fluid leaks in endonasal transsphenoidal pituitary surgery: surgical experience in a series of 1002 patients. J Neurosurg. 2018;129(2):425-9

7. Gondim JA, Almeida JPC, Albuquerque LAF, Schops M, Gomes E, Ferraz T, et al. Endoscopic endonasal approach for pituitary adenoma: surgical complications in 301 patients. Pituitary 2011 Jun;14(2):174-83

8. Zhang C, Ding X, $\mathrm{Lu} \mathrm{Y,} \mathrm{Hu} \mathrm{L,} \mathrm{Hu} \mathrm{G.} \mathrm{Cerebrospinal} \mathrm{fluid}$ rhinorrhoea following transsphenoidal surgery for pituitary adenoma: experience in a Chinese centre. Acta Otorhinolaryngol Ital. 2017 Aug;37(4):303-7

9. Berker M, Aghayev K, Yücel T, Hazer DB, Onerci M Management of cerebrospinal fluid leak during endoscopic pituitary surgery. Auris Nasus Larynx. 2013 Aug;40(4):373-8
10. Berker M, Hazer DB, Yücel T, Gürlek A, Cila A, Aldur M, et al. Complications of endoscopic surgery of the pituitary adenomas: analysis of 570 patients and review of the literature. Pituitary. 2012 Sep;15(3):288-300

11. Gendeh BS. Extended applications of endoscopic sinus surgery and its reference to cranial base and pituitary fossa. Indian J Otolaryngol Head Neck Surg. 2010 Sep;62(3):264-76

12. Conger A, Zhao F, Wang X, Eisenberg A, Griffiths C, Esposito $\mathrm{F}$, et al. Evolution of the graded repair of CSF leaks and skull base defects in endonasal endoscopic tumor surgery: trends in repair failure and meningitis rates in 509 patients. Journal of Neurosurgery 2019 Mar;130(3):861-75

13. Umamaheswaran P, Krishnaswamy V, Krishnamurthy G, Mohanty S. Outcomes of Surgical Repair of Skull Base Defects Following Endonasal Pituitary Surgery: A Retrospective Observational Study. Indian J Otolaryngol Head Neck Surg. 2019 Mar;71(1):66-70

14. Locatelli D, Vitali M, Custodi VM, Scagnelli P, Castelnuovo P, Canevari FR. Endonasal approaches to the sellar and parasellar regions: closure techniques using biomaterials. Acta Neurochir (Wien). 2009 Nov;151(11):1431-7

15. Sanders-Taylor C, Anaizi A, Kosty J, Zimmer LA, Theodosopoulos PV. Sellar Reconstruction and Rates of Delayed Cerebrospinal Fluid Leak after Endoscopic Pituitary Surgery. J Neurol Surg B Skull Base. 2015 Aug;76(4):281-5

16. Sciarretta V, Mazzatenta D, Ciarpaglini R, Pasquini E, Farneti G, Frank G. Surgical repair of persisting CSF leaks following standard or extended endoscopic transsphenoidal surgery for pituitary tumor. Minim Invasive Neurosurg. 2010 Apr;53(2):55-9.

17. Mehta GU, Oldfield EH. Prevention of intraoperative cerebrospinal fluid leaks by lumbar cerebrospinal fluid drainage during surgery for pituitary macroadenomas. J Neurosurg. 2012 Jun;116(6):1299-303

18. Jonathan GE, Sarkar S, Singh G, Mani S, Thomas R, Chacko AG. A randomized controlled trial to determine the role of intraoperative lumbar cerebrospinal fluid drainage in patients undergoing endoscopic transsphenoidal surgery for pituitary adenomas. Neurol India. 2018 Feb;66(1):133-8. 